\title{
Impact from Counterion Nature on Current Transfer Through Structural Fragments of Sulphocationic Resin
}

\author{
Myroslav Malovanyy ${ }^{1 *}$, Natalia Kononenko², Olga Demina² ${ }^{2}$ Kateryna Petrushka ${ }^{1}$ \\ 1 Viacheslav Chornovil Institute of Sustainable Development, Lviv Polytechnic National University, \\ Bandera str., 12, Lviv, 79013, Ukraine \\ 2 Faculty of Chemistry and High Technologies, Kuban State University, Stavropolskaya str., 149, Krasnodar, \\ 350040, Russia \\ * Corresponding author's e-mail: myroslav.mal@gmail.com
}

\begin{abstract}
The parameters of an extended three-wire model of ion-exchange materials conductivity, which characterize the current particles flowing through various structural fragments of the ion exchanger, were calculated based on the concentration dependence of the sulphocationite KU-2 resin electrical conductivity in electrolyte solutions of different nature. It was shown that most of the current in the resin is transferred through the channel with a consecutive arrangement of conducting gel and solution phases, regardless of the counterion nature. The differences in model parameters for the resin in the salt and proton form, related to the specific mechanism of proton transfer, confirmed the adequacy of the applied approach to the estimation of the counterion nature effect on the current transfer in resin.
\end{abstract}

Keywords: ion-exchange resin; type of the counter-ions; extended three-wire model; conductivity.

\section{INTRODUCTION}

One of the most prospective ways of wastewaters and mine waters demineralization is electrodialysis. With the help of electrodialysis, demineralization and concentration of waters with the salinity content up to $12000 \mathrm{mg} / \mathrm{l}$ is possible with reaching of obtaining level of clean water up to $94 \%$, that is, the outgoing solution can be concentrated almost 20 times. It is important that the life cycle of membranes is economically attractive and long-lasting. Membrane ways of purification and assessment of impact of unpurified effluents on environment were the subject of multiple studies (Adamenko et al. 2016, Gomelya et al. 2014). However, among many studies, little attention is being paid to the practical application of electrodialysis impact of counterion nature on the current transfer through structural fragments of ionite.

Resins are used not only in ion-exchange technology, but also in electro-membrane processes as a filling between the membranes in the desalination cells of electrodialysis apparatus with maximum solution resistance. In order to simulate the processes of electrical mass transfer in such electrodialyzers with filler, it is necessary to have the information on transportation and structural parameters as well as the mechanism of the current transfer not only in the ion-exchange membrane (Berezina et al. 2008, Karpenko-Jereb et al. 2009, Demina et al. 2016b), but also in resin. Currently, there is plenty published data on the electrical conductivity of ion-exchange resin in electrolyte solutions of different nature, but the information on the mechanisms of the current transfer in these materials is not available.

In order to find the current particles flowing through various structural fragments of heterogeneous systems, a three-wire model originally developed for ion-exchange columns can be used. After completing this model with the equations of relationship between its parameters and structural parameters of two-phase models, an opportunity 
to use this enhanced model for describing the electrical conductivity of resins and membranes (Demina et al. 2014, Falina et al. 2017, Gnusin et al. 2009) appeared. Ion-exchange resins, as well as the membrane, are micro-heterogeneous materials, which consist of gel phases and inclusions of equilibrium solution. A gel phase of ion-exchange resin represents a set of hydrated ion pairs of a fixed ion - counter-ion, and its hydration capacity, which determines the amount of electrical conductivity of resin, depends on the ionic form of the latter.

The aim was to study the influence of counterion nature on the current transfer through the structural fragments of sulphocationite resin by analysing the parameters of an extended threewire model defined from the concentration dependence of electrical conductivity of resin in solutions of various electrolytes.

\section{METHODS AND MATERIAL}

The object of the study was sulphocationite KU-2 resin of different ionic forms. Solutions $\mathrm{HCl}, \mathrm{LiCl}, \mathrm{NaCl}$ and $\mathrm{KCl}$ were used as the equilibrium solutions. In order to assess the possibility of using electrodialysis with ion exchange filling in organizing environmental water treatment technologies, solution $\mathrm{NH}_{4} \mathrm{Cl}$ was also used, which is the basis of household wastewater. Before the study, the resin was subjected to chemical conditioning, sequentially processing the sodium chloride concentration of 350, 100 and $30 \mathrm{~g} / 1$, washed with distilled water and converted into the desired ionic form with a $10 \%$ solution of the corresponding salt or acid.

The static exchange capacity and moisture content of the resin was determined by standard methods. Mass fraction of water $(W, \%)$ was calculated using the formula:

$$
W=\frac{m-m_{1}}{m_{2}} \times 100 \%
$$

where: $m$-mass of the resin in the sample bottle before drying, $g$;

$m_{1}$ - mass of resin from the sample bottle after drying, $g$;

$m_{2}$ - mass of swollen resin sample, $g$.

Hydrated resin capacity (n), which is the average number of water molecules per one functional group was calculated by the equation:

$$
n=\frac{W}{P_{\mathrm{H}_{2} \mathrm{O}} Q}
$$

where: $P_{\mathrm{H} 2 \mathrm{O}}$-the mass of 1 mole of $\mathrm{H}_{2} \mathrm{O}$, equal to $18 \mathrm{~g} / \mathrm{mol}$;

$Q$ - exchange capacity of ion exchange material $\mathrm{mol} / \mathrm{g}$.

The electrical conductivity of resin $\left(\kappa_{\mathrm{r}}\right)$ was determined by centrifugation as described in (Gnusin et al. 2009). The following equation was used for calculation:

$$
\kappa_{r}=\hat{E}_{c} / R
$$

where: $\hat{E}_{c}-$ cell constant;

$R$ - cell resistance with resin after its centrifugation.

The value $\hat{E}_{c}$ was determined by measuring the resistance of the resin in the cell after bringing it into balance with isoconductive concentration of the solution $\left(C_{i s o}\right)$, in which the electrical conductivity of resin $\left(\kappa_{r}\right)$, its gel phase $\left(\kappa_{\text {iso }}\right)$ and the solution $(\kappa)$ are equal: $\kappa_{r}=\kappa_{\text {iso }}=\kappa$. The value $C_{i s o}$ was found graphically as the intersection of the concentration conductivity dependences $(1 / R)$ of resin and solution (Fig. 1), measured using the $U$-shaped cells (Gnusin at al. 2009).

\section{OBTAINED RESULTS AND THEIR DISCUSSION}

The physical and chemical characteristics of cation exchange KU-2 resin in a standard $0.1 \mathrm{M}$ $\mathrm{NaCl}$ solution are presented in Table 1. The impact of ionic form on moisture content in resin in $0.1 \mathrm{M}$ electrolyte solutions is shown in Figure 2 as $\mathrm{W}$ dependence from the counterion radius. As shown in the figure, the moisture content of the KU-2 resin depends on the nature of the counterion and naturally decreases with resin transition from $\mathrm{H}^{+}$to $\mathrm{NH}_{4}^{+}$-forms. The decrease in hydration characteristics of the resin in this series is connected with the increase in crystallographic radius of the counterion (Filippov et al. 2017) and, consequently, the decrease in ionic radius in the hydrated state in the same sequence (Baldanova et al. 2012). Previously, this pattern was noted for sulphocationite resins and membranes (Demina et al. 2016a).

The concentration dependences of the electrical conductivity of different ionic forms of KU-2 


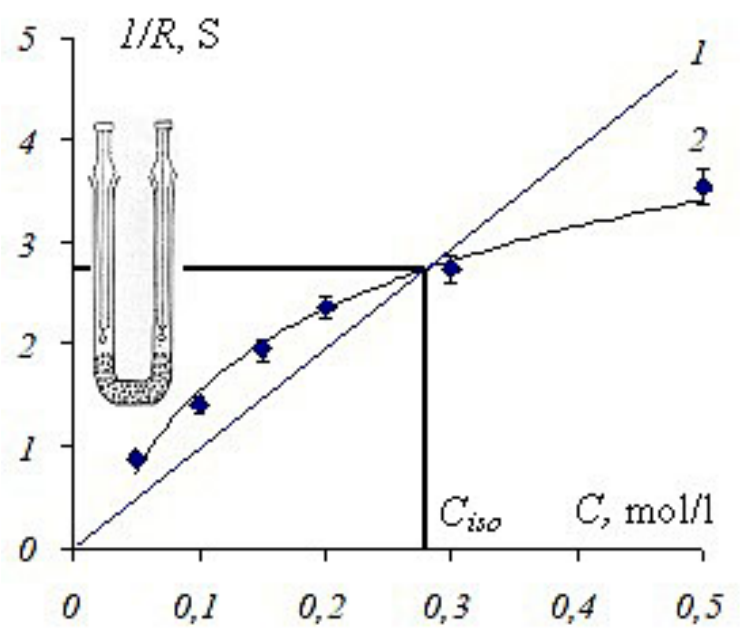

Fig. 1. Determining of isoconductivity concentration of KU-2 resin through U-shaped cells:

1 - solution conductivity; 2 - resin conductivity with a balanced solution

resin and solutions $\mathrm{HCl}, \mathrm{LiCl}, \mathrm{NaCl}, \mathrm{KCl}$ and $\mathrm{NH}_{4} \mathrm{Cl}$ are shown in Figure 3.

The comparison of Figure 2 and Figure 3 shows that the order of salt forms according to conductivity is opposite to the order of their location according to hydration capacity of resin and coincides with a series of mobility of the corresponding ions in the solution (Volkov et al. 2017). This obtained result is due to the decrease in mobility of counter-ions in ion exchangers because of the increase in the degree of their hydration and it is consistent with the literature data (Filippov et al. 2017). It should be noted that abnormally high conductivity of resin in $\mathrm{H}+$-form is connected with the fact that proton transfer in ion-exchange materials, as well as its transfer in aqueous acids, occurs on a relay mechanism.

The concentration dependences of electrical conductivity of resin in electrolyte solutions of different nature were used to find the parameters of the extended three-wire model, according to which the current in the resin can proceed along three parallel channels: consistently through gel and solution (parameter a); only through gel (parameter b); only through the solution (parameter c). The shares of current flowing through the gel and solution in the combined channel are equal to $d$ and $e$ (Fig. 4), respectively.

Basic equations models:

$$
\begin{gathered}
K_{r}=\frac{a K_{d}}{e+d K_{d}}+b K_{d}+c \\
a+b+c=1 \\
e+d=1
\end{gathered}
$$

connect the parameters characterizing fractions of the current passing through these channels $(a, b, c, d, e)$ and the parameters $K_{r}$ and $K_{d}$, representing the electrical conductivity of resin $\left(\kappa_{\mathrm{r}}\right)$ and its gel phase $\left(\kappa_{\text {iso }}\right)$, normalized to the conductivity of the solution $(\kappa)$ :

$$
K_{r}=\frac{\kappa_{r}}{\kappa} \text { and } K_{d}=\frac{\kappa_{i s o}}{\kappa}
$$

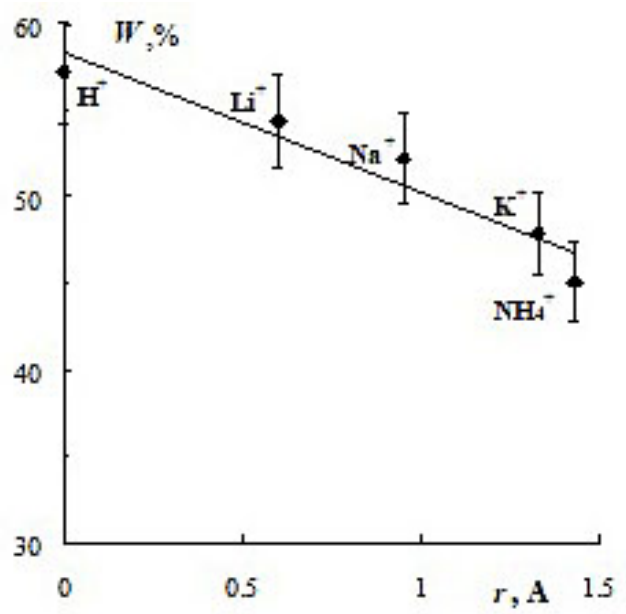

\begin{tabular}{|c|c|c|c|c|}
\hline Resin & Structural chain & $\frac{\mathrm{mmol}}{\mathrm{m}}$ & $\begin{array}{c}\mathrm{W} \% \\
0.1 \mathrm{M} \mathrm{NaCl}\end{array}$ & 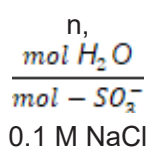 \\
\hline $\mathrm{KU}-2$ & $-\mathrm{CH}-\mathrm{CH}_{2}-$ & $3.5 \pm 0.2$ & $52.2 \pm 2.6$ & $8.2 \pm 0.4$ \\
\hline
\end{tabular}

Fig. 2. Moisture content of KU-2 resin, depending on the counter-ion radius

Table 1. Physical and chemical properties of the investigated KU-2 resin 
The parameters of the three-wire model for ion-exchange resin and membranes can be calculated only if they are linked with the parameters of a two-phase model of these materials conductivity, taking into account their micro-heterogeneity:

$$
\begin{gathered}
f=a e+b \\
b=f^{1 / \alpha} \\
c=(1-f)^{1 / \alpha} \\
a=1-(1-f)^{1 / \alpha}-f^{1 / \alpha} \\
e=(f-b) / a \\
d=1-(f-b) / a
\end{gathered}
$$

The structural parameters of a two-phase conductivity model reflect the volume fraction of gel phase $(f)$ and the relative position of the leading phases of gel and solution $(\alpha)$ in the swollen polymer, respectively (Gnusin et al. 2004, Nikonenko et al. 2007). Parameter $a$ changes from -1 to $+1: a=1$ corresponds to a parallel arrangement of phases on the transport axis $a=-1-$ sequential, $a \rightarrow 0$ - chaotic.

The authors (Berezina et al. 2008) managed to develop a method, which allows to calculate all the model parameters $a, b, c, d, e, f$ based on one concentration dependence of resin conductivity. The parameters of the extended three-wire model of the KU-2 resin in different ionic forms, determined with the help of the developed (Demina et al. 2014) computer program, are presented as histograms in Figure 5.

The analysis of parameters $f$ and $a$ (Fig. 5) shows that resin in $\mathrm{K}^{+}$- and $\mathrm{Na}^{+}$-forms has an identical structure: almost the same ratio of bulk particles of gel and solution phases (parameter $f$ about 0.85 ) and the similar, close to chaotic, relative positions of the leading phases (parameter $a$ less than 0.15 ). The transformation of resin into $\mathrm{Li}^{+}$-form is accompanied by the increase in degree of the leading phases order, indicating the increase in parameter $\alpha$ to 0.2 . This is due to a significant increase in the hydration capacity of the resin as a result of strong structuring actions of $\mathrm{Li}^{+}$ion over the nearest water molecules.

Transition of resin into the proton form is accompanied by a decrease in the volume fraction of gel phase and an increase in the volume

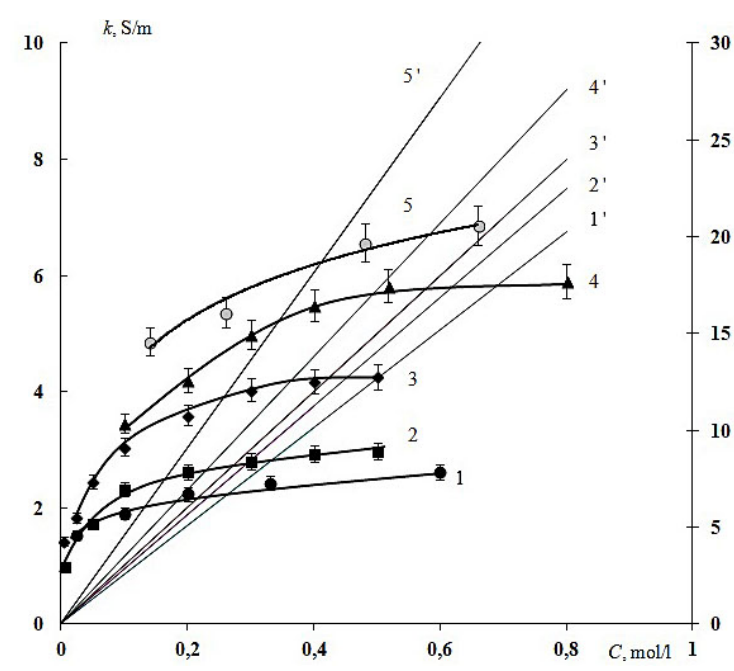

Fig. 3. Concentration dependences of the conductivity of KU-2 resin $(1-5)$ in different solutions and conductivity of electrolyte solutions ( 1 '- 5 '): 1 , 1' - LiCl; 2, 2' - $\mathrm{NaCl} ; 3$, 3' - KCl; 4, 4' - $\mathrm{NH}_{4} \mathrm{Cl}$; 5, $5^{\prime}-\mathrm{HCl}$ (curves 5 and 5 ' refer to the right axis)

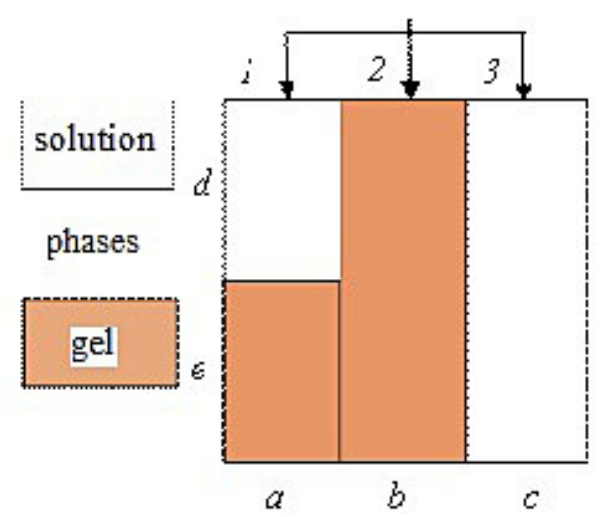

Fig. 4. Schematic representation of the three-wire model of ion-exchanger conductivity

fraction of the equilibrium solution. Thus, there is a subsequent ordering of the resin pattern (growth of the $a$ parameter) as a result of the additional areas formation with parallel connection of gel and solution phases in the swollen polymer.

The $a, b, c, d$ and $e$ parameters, describing the way of the current flow through structural fragments of the swollen polymer, complement the information about its internal structure. Figure $5 \mathrm{~b}$ presents parameter values of a three-wire model $(a, b, c)$ of KU-2 resin of different ionic forms. The figure shows that regardless of the nature of the counter-ion, the bulk of current is transferred through the channel of consistent gel and solution phases (parameter $a$ ). Transition of resin from one ionic form into another is accompanied by the redistribution of current paths in the resin. At the 
a)

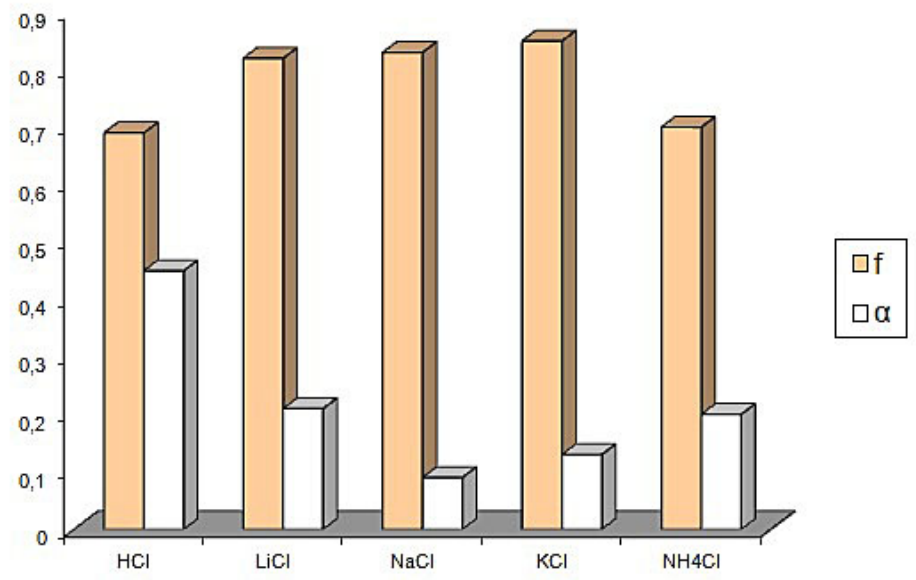

b)

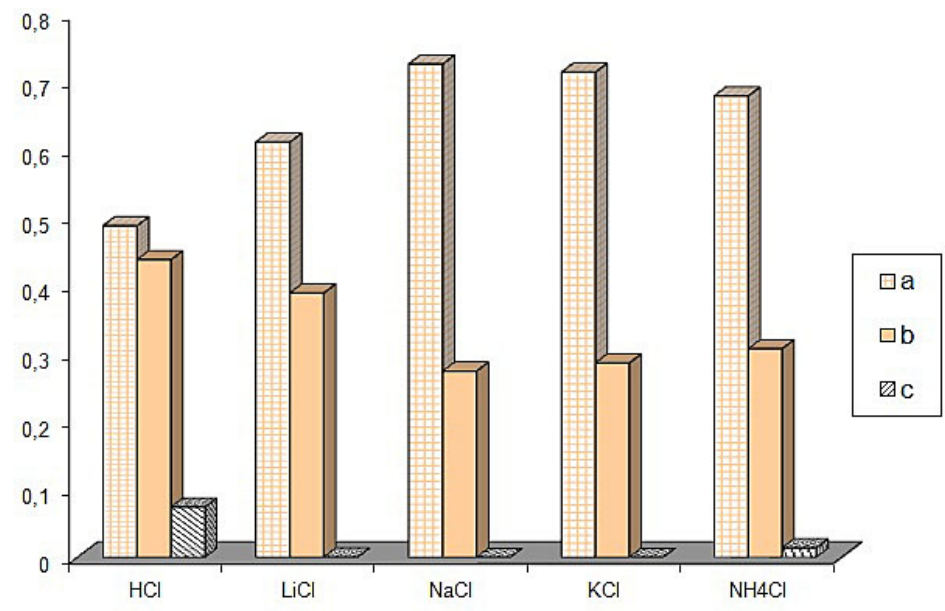

c)

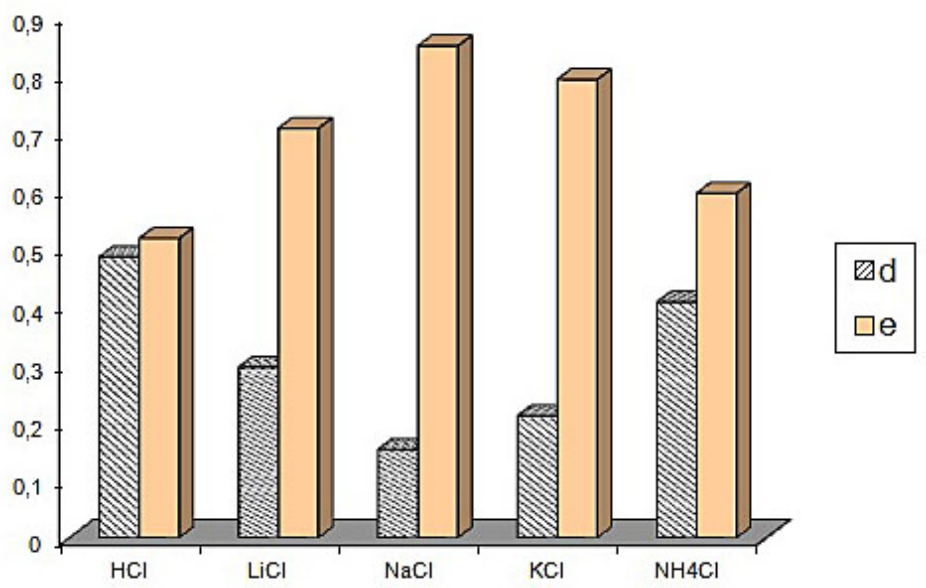

Fig. 5. Model parameters for KU-2 resin in different ionic forms

same time, as for the ion exchange membranes, including those made from KU-2 resin, it was found that the bulk of current, about $60 \%$, is transferred through the channel of pure gel (parameter $b$ ) and is almost independent from the nature of the polymer matrix and the specific moisture capacity of the membrane (Demina et al. 2014).

It should be noted that a resin granule in a salt form almost does not have throughout pores filled with an equilibrium solution. The part of current flowing through the channel $c$ is negligible for resin in salt forms (Fig. 5b). Transition of resin into the proton form is accompanied by the formation of a channel filled with equilibrium solution in the structure of the polymer, by reducing the volume fraction of the gel phase (Fig. 5a) and, consequently, the increase in the volume fraction of the solution. However, the fraction of the 
current passing through the channel $c$, in this case also does not exceed 0.1

Figure $5 \mathrm{c}$ shows the impact of counter-ion nature on the ratio of conductivity in solution (parameter $d$ ) and gel (parameter $e$ ) the combined channel $a$. As can be seen from the figure, in salt forms of the resin in a serial connection of the conducting phases, current transfer is dominant in gel (e parameter is $0.7-0.8$ ), whereas for the resin in proton form, fractions of current flowing through gel and solution in the combined channel are almost identical. Special distribution of current on the conducting channels in this case, is apparently associated with the relay mechanism of proton transfer, both in solution and in ion-exchangers.

The analysis of the model parameters for KU-2 resin in $\mathrm{NH}_{4}^{+}$-form (Fig. 5a-c) indicates that they are intermediate between the parameters of resin in salt and proton forms. This is due to $\mathrm{NH}_{4} \mathrm{Cl}$ hydrolysis, when resin is in a combined $\mathrm{NH}_{4}^{+}$- and $\mathrm{H}^{+}$-form.

\section{CONCLUSIONS}

The analysis of the parameters of the expanded three-wire conduction model of ion exchange resin in different ionic form showed that regardless of the counter-ion nature, the bulk of the current in resin is transferred through a channel with sequential leading phases of gel and solution. The differences between the model parameters for the resin in salt and proton forms are associated with a particular mechanism of proton transfer confirm the adequacy of the approach for assessing the impact of counter ion nature on carrying current through the structural fragments of sulphokationite resin. Intermediate position of resin in $\mathrm{NH}_{4}^{+}$-form is associated with the partial transfer of resin into $\mathrm{H}^{+}$-form through $\mathrm{NH}_{4} \mathrm{Cl}$ hydrolysis. The obtained information has both theoretical and practical importance. It allows for more efficient use of sulfocationite as intermembrane filler in electrodialysis apparatuses while processing aqueous solutions of different composition.

\section{REFERENCES}

1. Adamenko Ya., Coman M. 2016. The Methodology of Decision-Making within Procedures of Environmental Impact Assessments. Wulfenia Journal, 23(6), 377-384.

2. Baldanova D.M., Tanganov B.B. 2012. Plazmeno-gidrodinamicheskaya kontseptsiya sostoyaniya ionov v rastvorakh elektrolitov $\mathrm{v}$ otsenke nekotorykh svoystv. RAYe, Moscow.

3. Berezina N.P., Kononenko N.A., Dyomina O.A., Gnusin N.P. 2008. Characterization of ion-exchange membrane materials: properties vs structure. Advances Colloid Interface Sci., 139, 3-28.

4. Demina O.A., Falina I.V. Raschet model'nykh parametrov ionoobmennykh materialov $\mathrm{v}$ ramkakh rasshirennoy trekhprovodnoy modeli. A.s. 2014662877 RF, № 2014660629; zayavl. 20.10.14; opubl. 10.12.14.

5. Demina O.A., Falina I.V., Kononenko N.A., Demin A.V. 2016a. Effect of Counter- and Co-Ions on the Structural Transport Parameters of Sulfoacid Cationite Membranes. Russian Journal of Physical Chemistry A, 90(8), 1633-1638.

6. Demina O.A., Kononenko N.A., Falina I.V. 2014. New Approach to the Characterization of Ion Exchange Membranes Using a Set of Model Parameters. Petroleum Chemistry. 54(7) 515-525.

7. Demina O.A., Shkirskaya S.A., Kononenko N.A., Nazyrova E.V. 2016b. Assessing the Selectivity of Composite Ion-Exchange Membranes within the Framework of the Three-Wire Model of Conduction. Russian Journal of Electrochemistry, 52(4) 291-298.

8. Falina I.V., Demina O.A., Kononenko N.A., Annikova L.A. 2017. Influence of inert components on the formation of conducting channels in ionexchange membranes. Journal of Solid State Electrochemistry, 21(3) 767-775.

9. Filippov A.N., Kononenko N.A., Demina O.A. 2017. Diffusion of Electrolytes of Different Natures through the Cation-Exchange Membrane. Colloid Journal, 79(4) 556-566.

10. Gnusin N.P., Demina O.A., Annikova L.A. 2009. Method of model parameter calculation of for ionexchange resin. Russian J. Electrochemistry, 45(4), 490-495.

11. Gomelya, M.D., Trus, I.M., Radovenchyk, I.V. 2014. Influence of stabilizing water treatment on weak acid cation exchange resin in acidic form on quality of mine water nanofiltration desalination. Naukovyi Visnyk Natsionalnoho Hirnychoho Universytetu, 5, 100-105.

12. Karpenko-Jereb L.V., Berezina N.P. 2009. Determination of structural. selective electrokinetic and percolation characteristics of ion-exchange membranes from conductive data. Desalination, 245, 587-596.

13. Nikonenko V.V., Pis'menskaya N.D., Istoshin A.G., Zabolotskii V.I., Shudrenko A.A. 2007. Generalization and prognostication of mass exchange characteristics of electrodialyzers operating in overlimiting and compartmentation method. Russian J. Electrochemistry, 43(9), 1069-1081.

14. Volkov A.I., Chernik A.A. Spravochnik po elektrokhimii. Knizhnyy dom, Moscow. 2017. 